\title{
Comparison of Conventional and Ultrasound Assisted Supercritical Carbon Dioxide Extraction of Curcumin from Turmeric (Curcuma longa L.)
}

\author{
Kimthet Chhouk ${ }^{1,2, a,{ }^{*}}$, Wahyudiono ${ }^{1}$, Hideki Kanda ${ }^{1}$, and Motonobu Goto ${ }^{1, b}$ \\ 1 Department of Chemical Engineering, Nagoya University, Furo-cho, Chikusa-ku, Nagoya 464-8603, Japan \\ 2 Department of Chemical Engineering and Food Technology, Institute of Technology of Cambodia, \\ Russian conf. Blvd, Phnom Penh, Cambodia \\ E-mail: acthet@itc.edu.kh (Corresponding author), bmgoto@nuce.nagoya-u.ac.jp
}

\begin{abstract}
Recently, ultrasound assisted supercritical fluid is used for extraction the valuable compounds from a number of plant materials as an alternative to conventional method because it can enhance the extraction rate and yield. Curcumin is an important component of turmeric (Curcuma longa L.) with many useful functions to human health. The objective of this study is using ultrasonic assisted supercritical carbon dioxide (USC$\mathrm{CO}_{2}$ ) to extract curcumin from turmeric and compared to conventional method. The effect of operating conditions on extraction, including temperature $\left(40-60{ }^{\circ} \mathrm{C}\right)$, pressure (15-25 MPa), extraction time (30-120 min), $\mathrm{CO}_{2}$ flow rate $(2-4 \mathrm{~mL} / \mathrm{min})$ and percentage of cosolvent $(10-20 \% \mathrm{v} / \mathrm{v})$ were also studied. The result shows that the high extraction yield of $7.17 \% \mathrm{w} / \mathrm{w}$ and curcumin content of $1.69 \% \mathrm{w} / \mathrm{w}$ were achieved at temperature of 50 ${ }^{\circ} \mathrm{C}$, pressure of $25 \mathrm{MPa}$, extraction time of $90 \mathrm{~min}, \mathrm{CO}_{2}$ flow rate of $3 \mathrm{~mL} / \mathrm{min}$ with $10 \%$ cosolvent. Compared to conventional method, USC- $\mathrm{CO}_{2}$ could provide higher curcumin content in extraction yield in a shorter extraction time. Scanning electron microscopy (SEM), thermal gravity (TG), and fourier transform infrared spectroscopy (FTIR) was used to analyse turmeric undergoing USC- $\mathrm{CO}_{2}$ and conventional extraction and showed that ultrasound could break down the cell walls and remove some functional groups from plant materials, resulting an increase the selectivity of compounds in extraction yield.
\end{abstract}

Keywords: $\mathrm{SC}-\mathrm{CO}_{2}$ extraction, turmeric, ultrasound, scanning electron microscopy.

ENGINEERING JOURNAL Volume 21 Issue 5

Received 17 January 2017

Accepted 21 March 2017

Published 29 September 2017

Online at http://www.engj.org/

DOI:10.4186/ej.2017.21.5.53 


\section{Introduction}

Turmeric (Curcuma longa L.) contains curcuminoids, which are antioxidant substances with many biological properties, including anticancer, antibacterial and antiviral activities [1-3]. Among curcuminoids, curcumin is the most representative. Recent studies show that curcumin is currently used in dietary spice, foods, textile coloring and medicines due to its beneficial properties, such as anti-inflammatory, anti-bacterial, antifungal, antimicrobial, anti-carcinogenic activities, also contributing to the treat multiple myeloma, Alzheimer's, psoriasis, myelodysplastic syndrome and anti-human immunodeficiency virus (Anti-HIV) cycle replication. Because of the curcumin benefits, there is a great interest in developing new technology to extract such compounds with high purity [4-6].

Extraction of functional compounds from raw material is a promising area in the food and pharmaceutical industries. On the other hand, the quality of extracts from raw material strongly depends on the employed extraction method [7]. Various conventional extraction methods were used to extract functional compounds from plant materials such as Soxhlet extraction, maceration, and hydrodistillation. However, these methods can cause the degradation of labile compounds, require long extraction time, and leave the tract of toxic solvent in final product [8].

Supercritical fluid extraction is one of green and clean technology for food and pharmaceutical industries because it can maximize the recovery and quality of the extraction and minimize the energy cost due to faster and more selective compared to conventional methods. Moreover, the solubility can be improved by adding small amount of polar solvent. The use of cosolvent not only enhances the solubility, but also helps to disrupt the interaction of solute and solid material, resulting the increased in the transport of solute from solid pores to its surface $[9,10]$.

Adding ultrasound might improve the supercritical fluid extraction because ultrasound can generate the cavitation, resulting the breaking cell wall of plant materials. In this case, it facilitates the solvent penetrate in material and improve the mass transfer, thus increasing the extraction rate and yield [11]. Recently, ultrasound assisted supercritical fluid extraction has been applied to extract functional compounds from different raw materials such as blackberry bagasse [10], malagueta paper [11], adlay seed [12], Scutellaria barbata D. Don [13], grape marc [14], cumbaru almond [15], and, clove [16]. However, no reports have been found in the literatures that consider the Ultrasound assisted supercritical carbon dioxide (USC-CO extraction of curcumin from turmeric.

Therefore, the objective of this study was to investigate the extraction of curcumin from turmeric using USC- $\mathrm{CO}_{2}$. The effect of temperature, pressure, extraction time, $\mathrm{CO}_{2}$ flow rate and percentage of cosolvent on extraction yield and curcumin content were also evaluated. Moreover, the performance of USC-CO $\mathrm{CO}_{2}$ was check by comparison of extraction yield and curcumin content with conventional method.

\section{Experimental Section}

\subsection{Materials}

Turmeric with 12\% moisture content was bought from Tochimoto Tenkaido Co., LTD., Osaka, Japan. 99.9\% purity of $\mathrm{CO}_{2}$ was obtained from Sogo Kariya Sanso, Inc., Nagoya, Japan. 99.5\% ethanol, 99.5\% hexane were supplied by Wako Chemical, Japan. The acetonitrile was purchased at Kanto Chemical Co. Inc., Tokyo, Japan.

\subsection{Methods}

The flow chart of extraction and analysis is shown in Fig. 1.

\subsubsection{Sample preparation}

In order to homogenize and reduce mass resistance of substrate for extraction, the dried turmeric was ground in a knife mill (Model IFM 800, Iwatani international cooperation, Japan). After that, the solid turmeric particles were passed through the vertical vibratory sieve shaker. The mean diameter of the particles used in experiment was $0.5 \mathrm{~mm}$. Finally, sample was packaged in aluminium bag and stored under refrigerator at temperature of $4{ }^{\circ} \mathrm{C}$. 


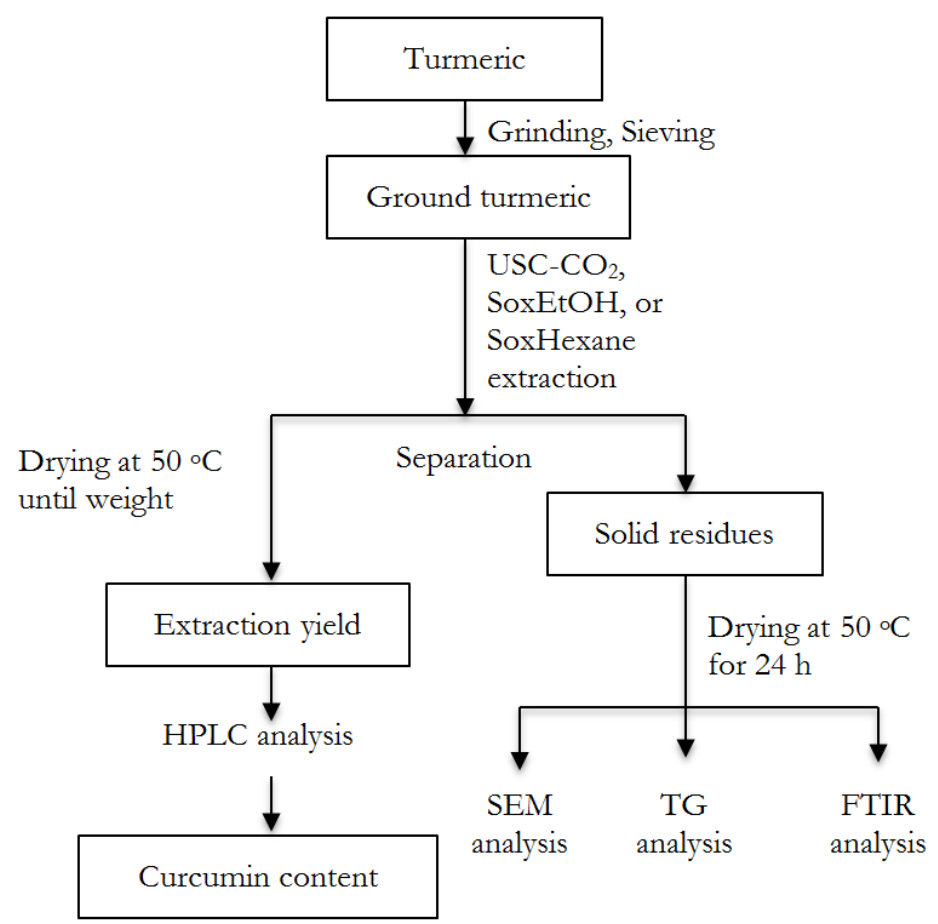

Fig. 1. The flow chart of extraction and analysis.

\subsubsection{Ultrasound assisted supercritical carbon dioxide $\left(\mathrm{USC}-\mathrm{CO}_{2}\right)$ extraction}

The USC- $\mathrm{CO}_{2}$ unit is composed of a $15 \mathrm{~mL}$ stainless steel cell (SUS 316, GL Sciences, Japan), which supports pressure up to $25 \mathrm{MPa}$. The unit is equipped with a chiller to control temperature of $\mathrm{CO}_{2}$, two high-pressure pumps, (PU-2080, JASCO, Japan) with capacity up to $10 \mathrm{~mL} / \mathrm{min}$, a electric heater to control the temperature of cell, water bath, ultrasound supplier (W-118, Honda, Japan), pressure gauge and backpressure regulator (BPR; AKICO, Japan) to keep the desired pressure constant. The schematic diagram of USC- $\mathrm{CO}_{2}$ extraction is illustrated in Fig. 2.

The extractor was filled with $1 \mathrm{~g}$ of ground sample and void volume was completed with glass beads on the top and bottom. The extraction process was carried out at various values of the operating condition: temperature $\left(40,50,60{ }^{\circ} \mathrm{C}\right)$, pressure $(15,20,25 \mathrm{MPa}), \mathrm{CO}_{2}$ flow rate $(2,3,4 \mathrm{~mL} / \mathrm{min})$, and colsolvent $(10$, $15,20 \%$ ). In order to study the dynamic of extraction process, extract time was performed at 30,60, 90 , $120 \mathrm{~min}$. Ultrasound power of $45 \mathrm{kHz}$ and $600 \mathrm{~W}$ (Ultrasonic multi cleaner W-118, Honda, Japan) was applied during extraction. After extraction, the extract was collected and solvent was evaporated using rotary evaporator (SB-1200, Eyela Co. Ltd, Japan). Lastly, the extract was dissolved in ethanol and kept in refrigerator for further analysis and solid residues were dried and used for scanning electron microscope (SEM), thermogravimetry (TG), and fourier transform infrared spectroscopy (FTIR) analysis. Each experiment was conducted in duplicates or triplicates.

The extraction yield was measured by taking $1 \mathrm{~mL}$ of extract for the calculation. The extract was dried in an electric oven at $50{ }^{\circ} \mathrm{C}$ until the constant weight obtained. After that, it was cooled in a desiccator at room temperature before weighing to constant weight. The extraction yield was calculate by following Eq. (1):

$$
\% \text { Extraction Yield }=\frac{W_{\text {extract }} \times V_{\text {totalof extract }}}{W_{\text {raw }} \text { material }} \times 100
$$

where:

$\mathrm{W}_{\text {extract: }}$ Weight of extract in $1 \mathrm{~mL}$ of sample after oven drying, $\mathrm{g} / \mathrm{mL}$.

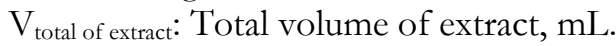

$\mathrm{W}_{\text {raw material }}$ : Weight of raw material used in extraction, g. 


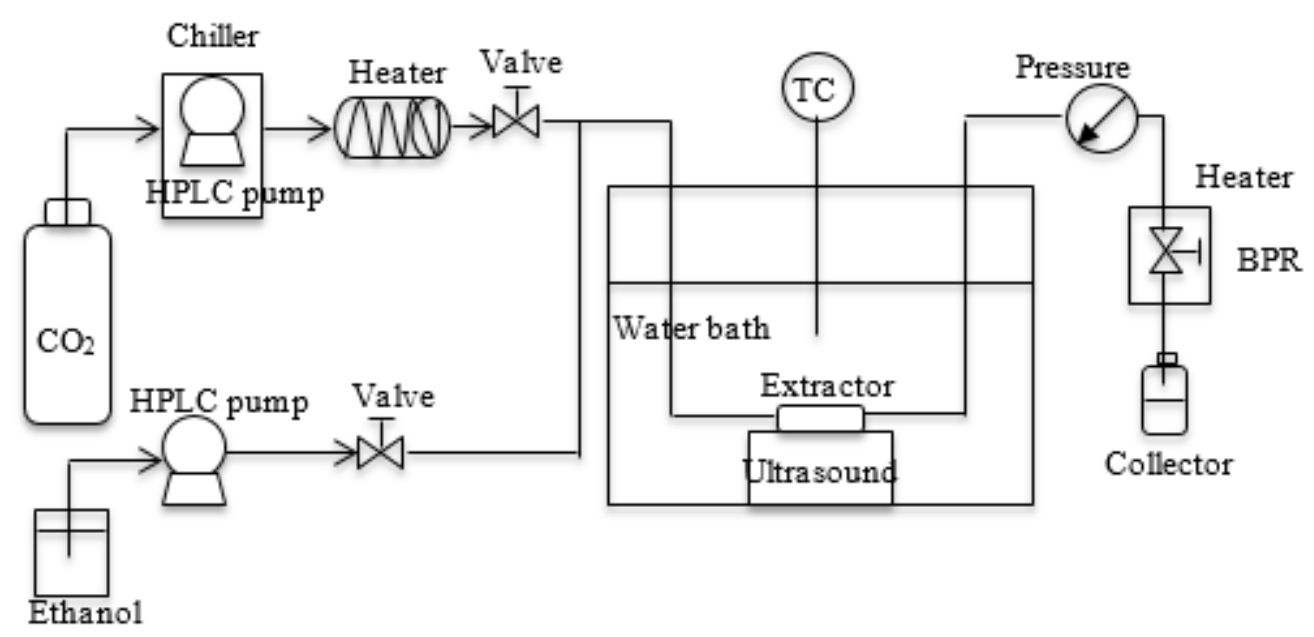

Fig. 2. Schematic diagram of USC-CO $\mathrm{CO}_{2}$ extraction system.

\subsubsection{Conventional extraction technique}

The Soxhlet extraction was also investigated and the results obtained were compared to the result of the USC- $\mathrm{CO}_{2}$ exaction process. Briefly, $5 \mathrm{~g}$ of sample was placed in a timble and extracted with $250 \mathrm{~mL}$ of ethanol or hexane for $6 \mathrm{~h}$. After that, the solvent was separated from extract by using a rotary evaporator.

\subsubsection{HPLC analysis}

The qualitative and quantitative analysis of curcumin in extract was performed by high performance liquid chromatography (HPLC) with diode array detector (SPD-M10AVP, Shimadzu, Japan), according to method described by Kiamahalleh et al. 2016 [6]. The sample was filtered with a $0.2 \mu \mathrm{m}$ disposable membrane filter and $20 \mu \mathrm{L}$ was injected. HPLC analysis was carried out using an Inertsil ODS-3 column (GL Sciences, Japan), with length of $250 \mathrm{~mm}$, internal diameter of $4.6 \mathrm{~mm}$ and thickness of $5 \mu \mathrm{m}$. The operating temperature of the chromatographic separation was maintained at $40{ }^{\circ} \mathrm{C}$. The mixture of acetonitrile and water $(90: 10 \mathrm{v} / \mathrm{v})$ was used as mobile phase with a flow rate of $1 \mathrm{~mL} / \mathrm{min}$ and the separation was performed at a detection wavelength of $420 \mathrm{~nm}$.

\section{Results and Discussion}

\subsection{Effect of Extraction Time}

The effect of extraction time on extraction yield and curcumin content from turmeric was determined at temperature of $50{ }^{\circ} \mathrm{C}$, pressure of $25 \mathrm{MPa}, \mathrm{CO}_{2}$ flow rate of $3 \mathrm{~mL} / \mathrm{min}$ with $10 \%$ of cosolvent. The experimental extraction curved for extraction yield and curcumin content are exhibited in Fig. 3. The results shows in Fig. 3 indicated that the extraction time for the high extraction yield and curcumin content obtained by USC-CO ${ }_{2}$ were $60 \mathrm{~min}$ and $90 \mathrm{~min}$, respectively. The ultrasound can produce micro-stirring and solvent cavitation which can improve the extraction yield and curcumin content from turmeric due to the damage of cell wall of plant and an increase of mass transfer of solvent when ultrasound was applied in SC- $\mathrm{CO}_{2}$ extraction $[17,18]$. Kawamura et al. 2016 [18] also found that the extraction yield of luteolin and apigenin from the leaves of Perilla frutescans were enhanced using ultrasound assisted $\mathrm{SC}-\mathrm{CO}_{2}$ extraction.

\subsection{Effect of Temperature}

To evaluate the effect of temperature on extraction yield and curcumin content, the extraction experiments were conducted at pressure of $25 \mathrm{MPa}, \mathrm{CO}_{2}$ flow rate of $3 \mathrm{~mL} / \mathrm{min}$ with $10 \%$ ethanol as cosolvent, and extraction time of $90 \mathrm{~min}$. Fig. 4 shows that extraction yield and curcumin content increased gradually with increasing temperature of 40 to $50^{\circ} \mathrm{C}$. When temperature increased from 50 to $60{ }^{\circ} \mathrm{C}$, the extraction yield 
and curcumin content was declined. At temperature of $50{ }^{\circ} \mathrm{C}$, the extraction yield and curcumin content were $7.17 \% \mathrm{w} / \mathrm{w}, 1.69 \% \mathrm{w} / \mathrm{w}$, respectively. It is notable to point that the temperature could effect on the density of $\mathrm{SC}-\mathrm{CO}_{2}$, the vapor pressure of solute and the desorption of the solute form material. Increasing temperature increased vapor pressure of solute from the material. Thus, the solubility of extraction yield and curcumin content increased $[19,20]$. However, when higher temperature was applied in extraction, extraction yield and curcumin content in extract may decrease because temperature might be continue to increase by the high intensity of ultrasound. Also, the oxidation of some compounds may occur due to the small amount of moisture content in material [21, 22]. Moreover, increasing temperature increased the volatility and diffusion of the solute and reduced the density of $\mathrm{CO}_{2}$. As the result, the solubility of curcumin decreased [17].

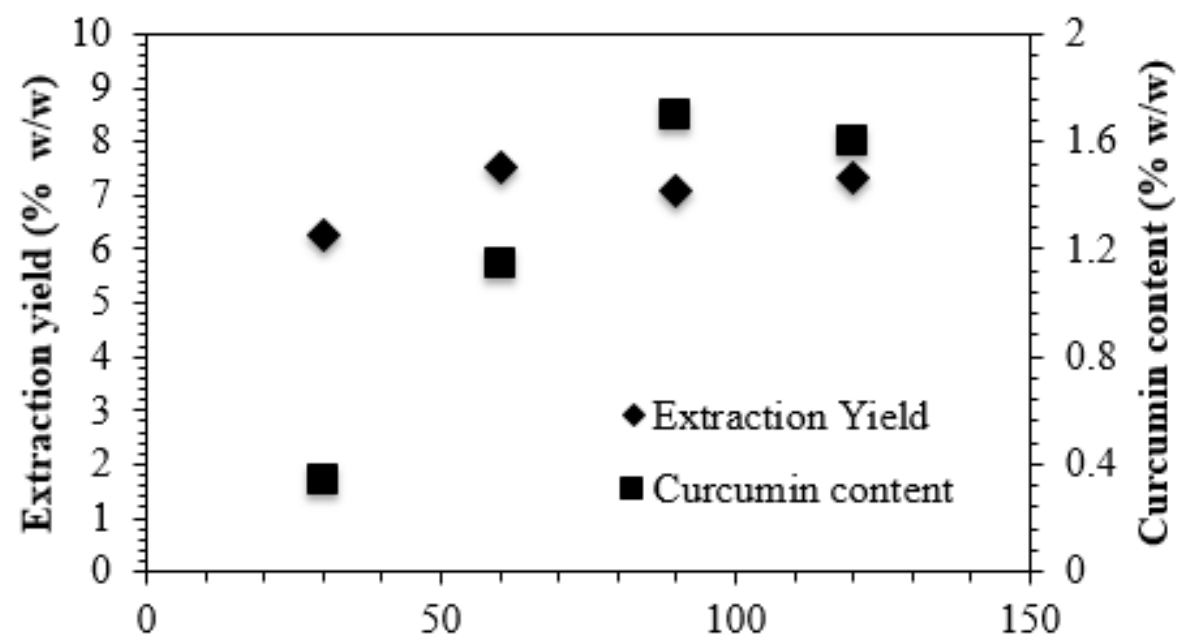

Extraction time (min)

Fig. 3. Effect of extraction times on extraction yield and curcumin content at $50{ }^{\circ} \mathrm{C}, 25 \mathrm{MPa}, \mathrm{CO}_{2}$ flow rate of $3 \mathrm{~mL} / \mathrm{min}$, and $10 \%$ cosolvent.

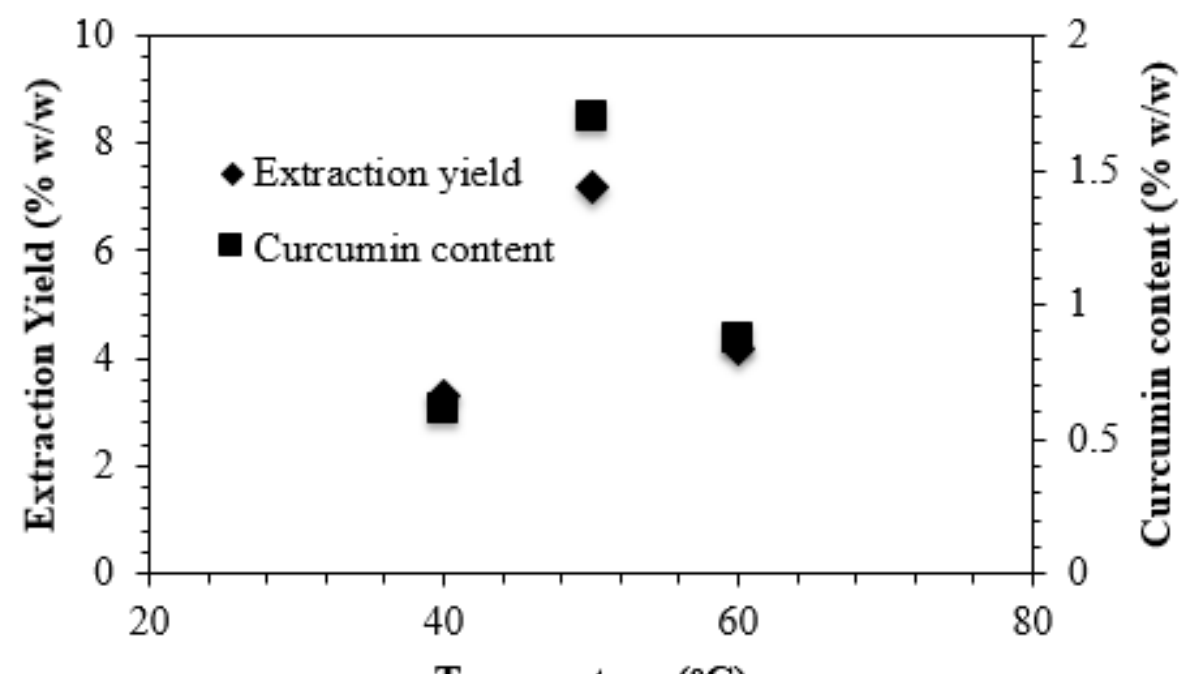

Temperature $\left({ }^{\circ} \mathrm{C}\right)$

Fig. 4. Effect of temperature on extraction yield and curcumin content at $25 \mathrm{MPa}, \mathrm{CO}_{2}$ flow rate of 3 $\mathrm{mL} / \mathrm{min}, 10 \%$ cosolvent and extraction time of $90 \mathrm{~min}$. 


\subsection{Effect of Pressure}

The effect of pressure on extraction yield and curcumin content is shown in Fig. 5. The extraction was conducted at temperature of $50{ }^{\circ} \mathrm{C}, \mathrm{CO}_{2}$ flow rate of $3 \mathrm{~mL} / \mathrm{min}$ with $10 \%$ ethanol as cosolvent, and extraction time of $90 \mathrm{~min}$. The result shows that the low extraction yield and curcumin content were obtained at pressure of 15 and $20 \mathrm{MPa}$. When pressure increased from 20 to $25 \mathrm{MPa}$, the extraction yield and curcumin content dramatically increased. The high extraction yield and curcumin were obtained at 25 $\mathrm{MPa}$. It can be explained that increasing pressure increased the density of $\mathrm{CO}_{2}$ and decreased the distance between the molecules. This increased the interaction of the solute and $\mathrm{CO}_{2}$. Therefore, the solubility of curcumin in USC- $\mathrm{CO}_{2}$ increase and this enhance the efficiency of extraction $[17,18]$. Similar to this study, Santos et al. 2016 [15], who extracted cumbaru oil from the cumbaru almond using ultrasonic assisted SC$\mathrm{CO}_{2}$ extraction, reported that the global yield of extraction increased with increasing pressure because increasing pressure increase the density of $\mathrm{CO}_{2}$.

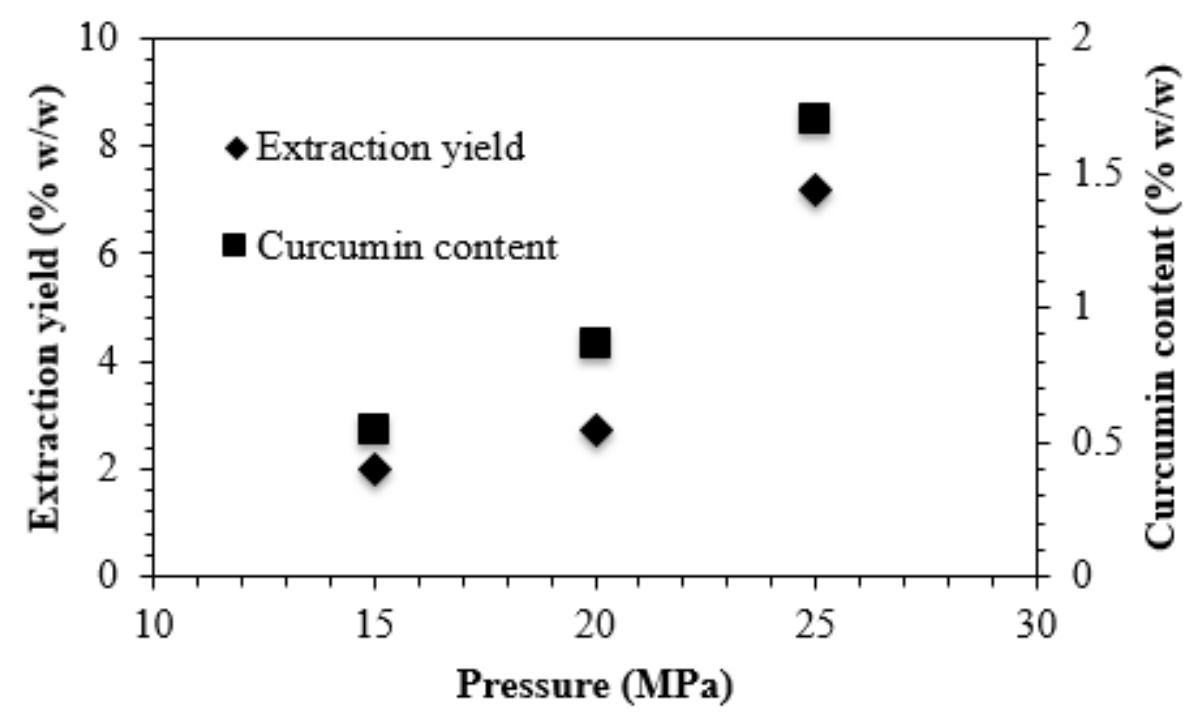

Fig. 5. Effect of pressure on extraction yield and curcumin content $50{ }^{\circ} \mathrm{C}, \mathrm{CO}_{2}$ flow rate of $3 \mathrm{~mL} / \mathrm{min}, 10 \%$ cosolvent, and extraction time of $90 \mathrm{~min}$.

\subsection{Effect of $\mathrm{CO}_{2}$ Flow Rate}

Figure 6 shows the effect of $\mathrm{CO}_{2}$ flow rate on extraction yield and curcumin content. The extraction experiments were done at temperature of $50{ }^{\circ} \mathrm{C}$, pressure of $25 \mathrm{MPa}$, extraction time of $90 \mathrm{~min}$, and cosolvent percentage constant with varying the $\mathrm{CO}_{2}$ flow rate at three levels $(2,3$, and $4 \mathrm{~mL} / \mathrm{min})$. According to Fig. 6, the extraction yield and curcumin content dramatically augmented when the $\mathrm{CO}_{2}$ flow rate increase from 2 to $3 \mathrm{~mL} / \mathrm{min}$. Then, the extraction yield and curcumin content was slightly declined with increasing $\mathrm{CO}_{2}$ flow rate from 3 to $4 \mathrm{~mL} / \mathrm{min}$. It is possible that increasing $\mathrm{CO}_{2}$ flow rate increased the amount of $\mathrm{CO}_{2}$ molecule per unit volume that enters the extractor. Therefore, it increased the interaction of $\mathrm{CO}_{2}$ and solute. This could increase amount of extracted solute in extraction process. However, an increase in $\mathrm{CO}_{2}$ flow rate also provides the negative effect to the dissolution of compounds because the $\mathrm{CO}_{2}$ flow through the sample matrix by channelling when high $\mathrm{CO}_{2}$ flow rate was applied. This caused the shorter contact time between the solute and solvent. As a consequence, the solubility of desired compounds was decreased $[13,17]$.

\subsection{Effect of Cosolvent}

The effect of cosolvent on extraction yield and curcumin content is presented in Fig. 7. The extraction experiments were conducted at $50{ }^{\circ} \mathrm{C}$, pressure of $25 \mathrm{MPa}$, extraction of $90 \mathrm{~min}, \mathrm{CO}_{2}$ flow rate of 3 $\mathrm{mL} / \mathrm{min}$, and varying the cosolvent at three level $(10,15,20 \% \mathrm{v} / \mathrm{v})$. Figure 7 shows that the extraction yield and curcumin content seem constant with increasing of cosolvent from 10 to $20 \% \mathrm{v} / \mathrm{v}$. In this study the 
preferred percentage of cosolvent is $10 \% \mathrm{v} / \mathrm{v}$. This can be explained that addition of cosolvent increased the polarity of solvent and the contact time between solvent and solute. Thus, it could improve the solubility of polar compounds in extraction and enhance the extraction yield. Moreover, cosolvent can make matrix swell, this may allow the supercritical fluid penetrate into the matrix, resulting in increased the diffusion of solute in extraction [13, 23, 24].

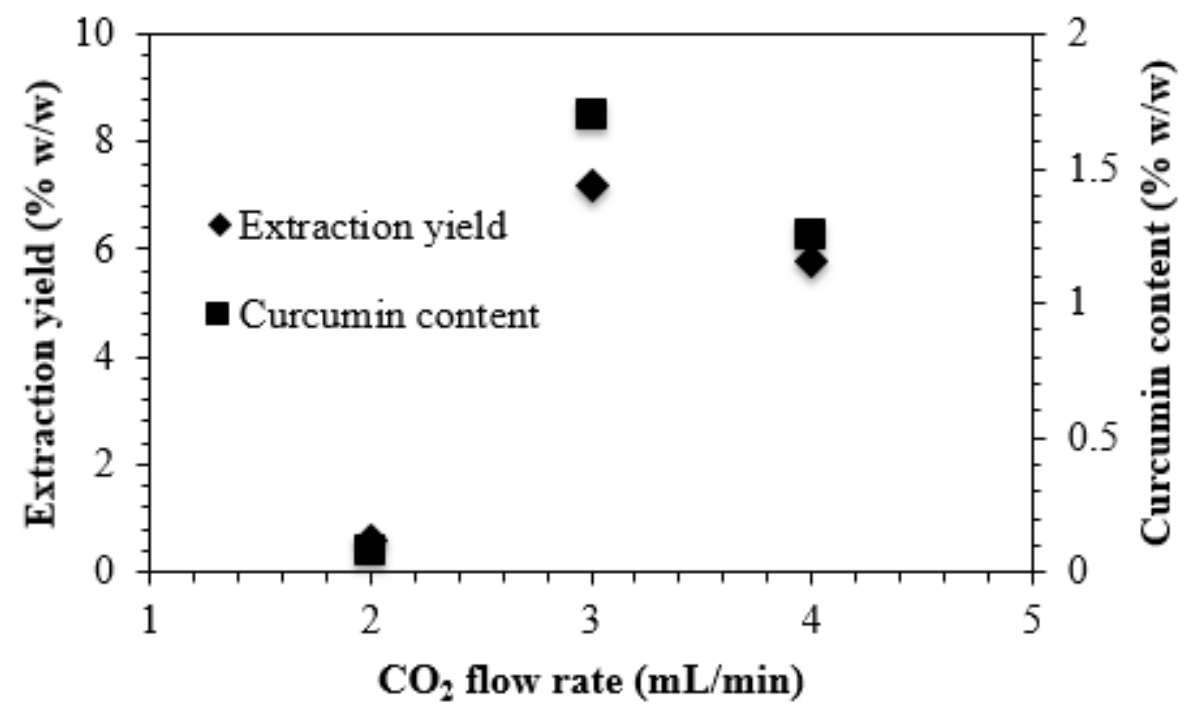

Fig. 6. Effect of $\mathrm{CO}_{2}$ flow rate on extraction yield and curcumin content $50{ }^{\circ} \mathrm{C}, 25 \mathrm{MPa}, 10 \%$ cosolvent, and extraction time of $90 \mathrm{~min}$.

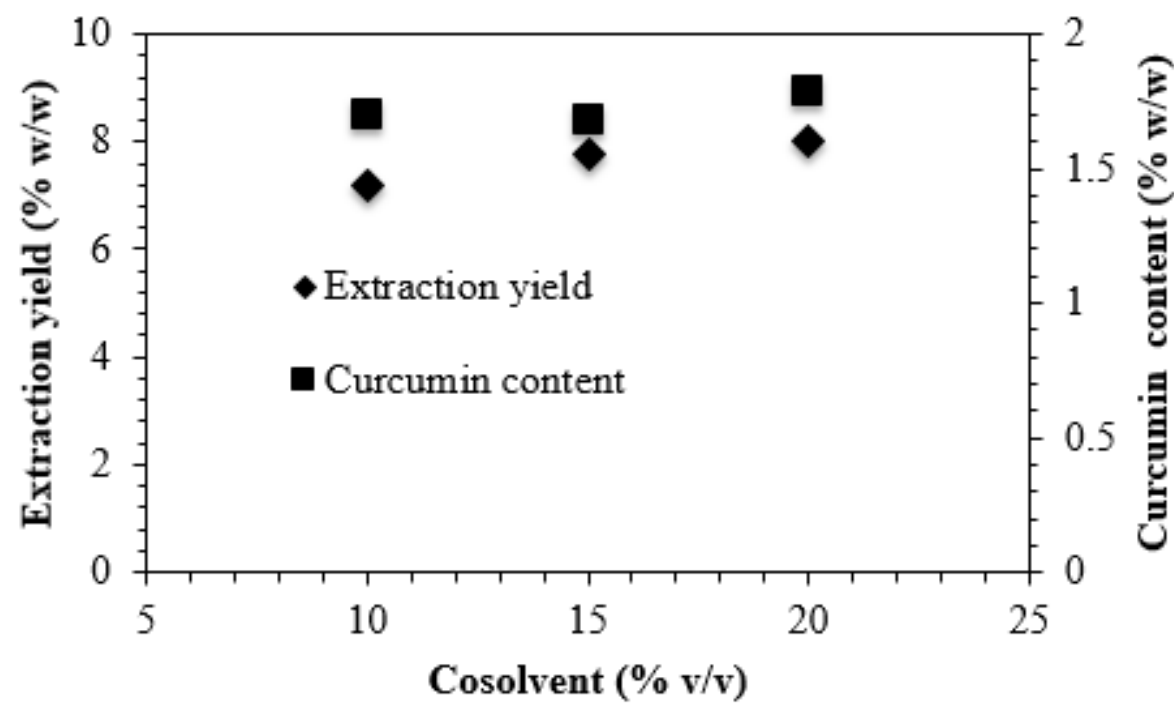

Fig. 7. Effect of percentage of cosolvent on extraction yield and curcumin content $50{ }^{\circ} \mathrm{C}, 25 \mathrm{MPa}, \mathrm{CO}_{2}$ flow rate of $3 \mathrm{~mL} / \mathrm{min}$, and extraction time of $90 \mathrm{~min}$.

\subsection{Comparison with Soxhlet Extraction}

Based on experiment result above, the high extraction yield and curcumin content from turmeric using USC- $\mathrm{CO}_{2}$ was at temperature of $50{ }^{\circ} \mathrm{C}$, pressure of $25 \mathrm{MPa}$, extraction time of $90 \mathrm{~min}$, flow rate of $\mathrm{CO}_{2}$ of $3 \mathrm{~mL} / \mathrm{min}$ with $10 \%$ cosolvent. The extraction yield and curcumin content obtained with this condition (USC- $\mathrm{CO}_{2}$ ) were compared with those obtained with Soxhlet extraction using ethanol (SoxEtOH) and hexane (SoxHexane). Figure 8 (a) and (b) show that the extraction yield obtained with USC-CO 2 was comparable with that obtained with SoxEtOH. The low extraction yields was obtained by using SoxHexane. 
On the other hand, the curcumin content in extract of USC- $\mathrm{CO}_{2}$ were greater than those obtained with SoxEtOH and SoxHexane. These results demonstrate that USC-CO $\mathrm{CO}_{2}$ have the potential to extract curcumin from turmeric because ultrasound occurred in extraction helped to disrupt the cell water and increase mass transfer, thus reduce the amounted of solvent needed, temperature, and extraction time.
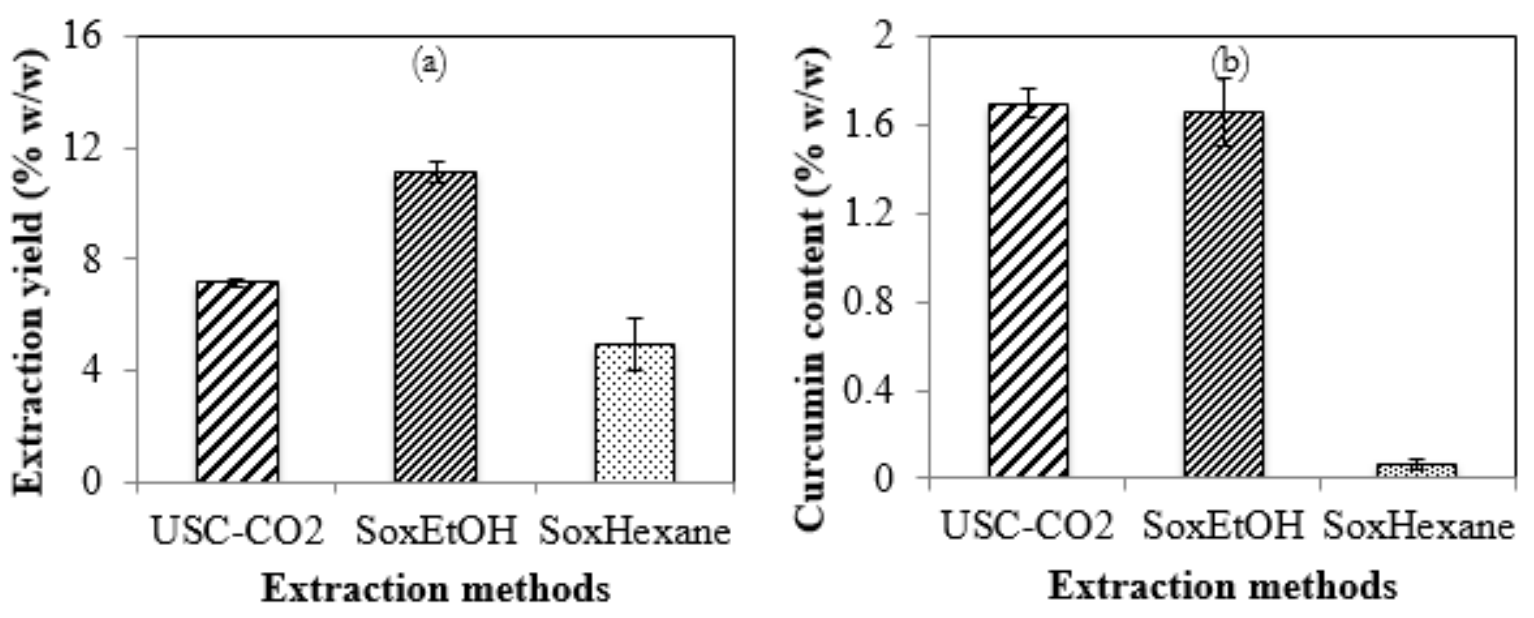

Fig. 8. Comparison of extraction yield and curcumin content with USC- $\mathrm{CO}_{2}$, SoxEtOH, and SoxHexane.

\subsection{Extraction Mechanism}

In order to investigate the effect of USC- $\mathrm{CO}_{2}$ on solid matrix, surface morphology of turmeric was analyzed by using SEM. Figure 9 show the images obtained by SEM on turmeric before extraction and after USC- $\mathrm{CO}_{2}$, SoxEtOH, and SoxHexane extraction. Based on Fig. 9, it is clearly seen that sample that the surface of raw material seems hard and does not present any cracks or pores. However, sample after USC$\mathrm{CO}_{2}$, SoxEtOH, SoxHexane extraction had the presence of cracks and pores on its surface. These micrographs showed that the surface morphology of turmeric was changed after extraction. It is notable that there were some cracks and pores appears on surface morphology of solid reside after SoxHexane, but the pore size on this surface was smaller than that on the surface of the residue after USC- $\mathrm{CO}_{2}$ and SoxEtOH extraction. Even though USC- $\mathrm{CO}_{2}$ consumed less amount of solvent and shorter extraction time compared to SoxEtOH, the surface morphology of residue after USC- $\mathrm{CO}_{2}$ and SoxEtOH extraction was similar because the ultrasound produced the cavitation, which disturbed the cell wall and open up the pore, leading to release of solute from material $[10,11]$. The degradation of material in extraction process is complicated due to the component joined to fiber by physical and chemical adsorption or embodied in cell of vegetable by unknown action. Ji et al. 2006 [25] explained the mechanism of ultrasound-assisted extraction as follow: first, the ultrasound waves propagated into the plant particle, resulting in breaking of some chemical bond of solute and plant material. Second, the high-speed micro-jet and high-pressure shock wave were generated by the collapse of cavitation, leading to make a hollow and erosion of external surface as well as the porous wall within the particle. Third, the turbulence wave created by ultrasound near the interfacial surface and porous within the particle increased mass transfer both external and internal surface. The mechanism of extraction of curcumin from turmeric by USC- $\mathrm{CO}_{2}$ maybe similar to mechanism proposed by Ji et al. First, the ultrasound creates the cavitation that generates bubbles. Then, the tiny bubble go through the particle and break down the chemical bond of curcumin with fiber in turmeric. The production of cavitation near surface of particle can facilitate swelling and hydration. This causes expansion in the pore of cell wall, leading to enhance mass transfer of curcumin from turmeric to solvent by diffusion and osmotic process [26]. Furthermore, ultrasound can disrupt the external and internal surface of turmeric which favors the washing out of the disrupt cell content, leading to increase the accessibility of the curcumin to solvent [10]. The mass transfer of fluid into the cavitation surface also can be accelerated by addition of ultrasound in extraction process [11]. By these reactions, the curcumin was extracted from turmeric. 


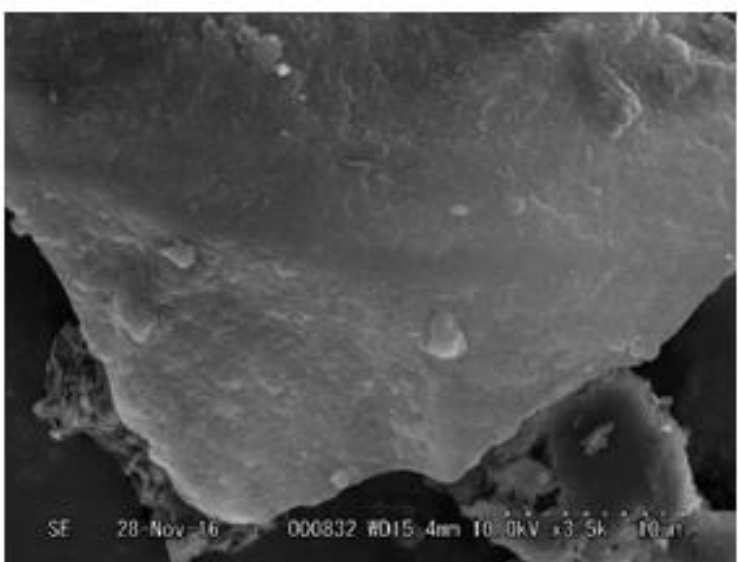

(a) Turmeric before extraction

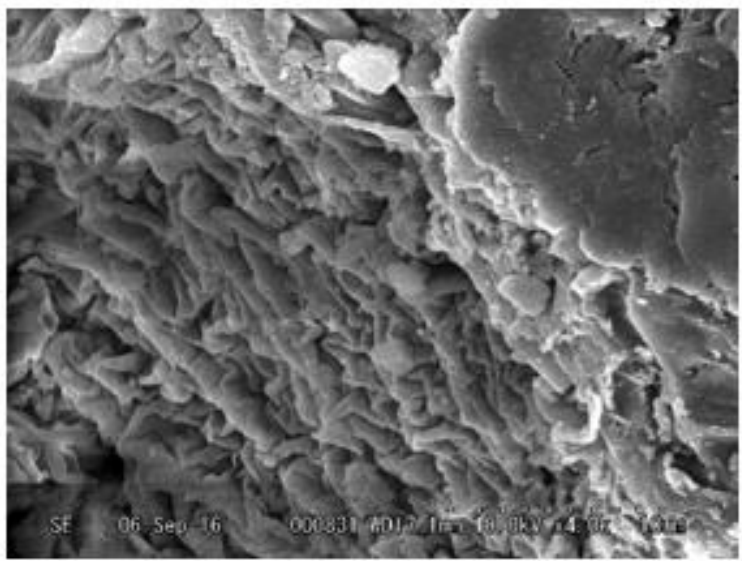

(c) Solid residue after SoxEtOH extraction

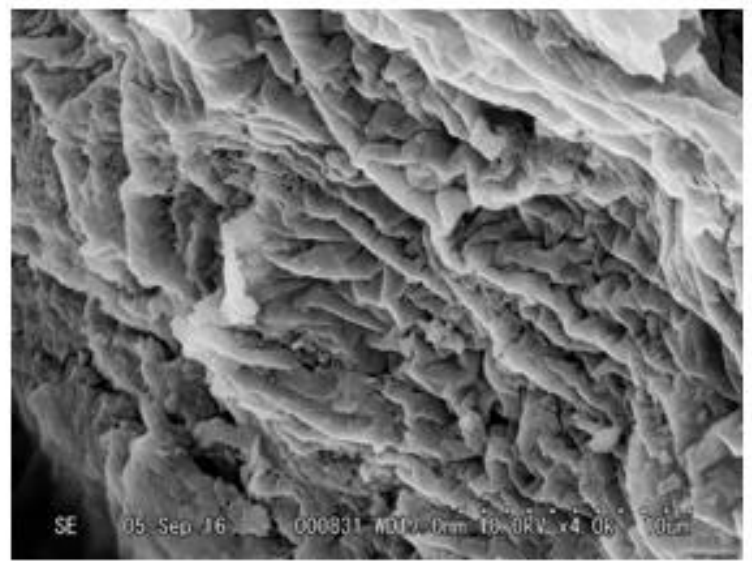

(b) Solid residue after USC-CO $\mathrm{CO}_{2}$ extraction

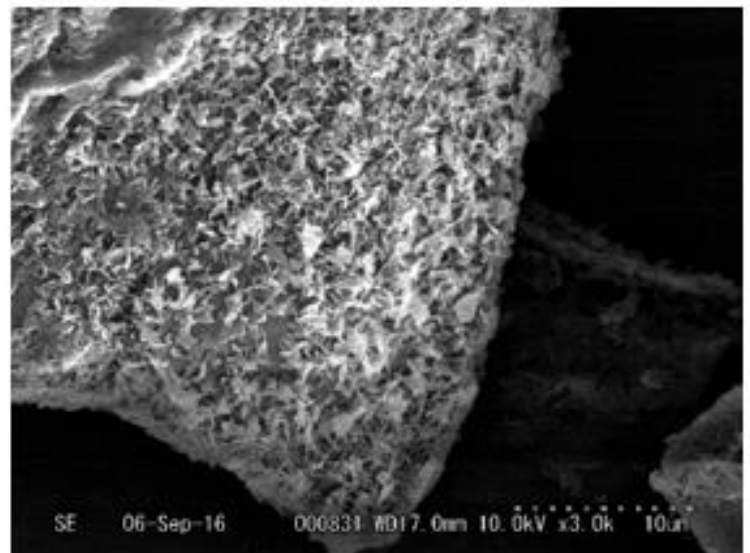

(d) Solid residue after SoxHexane extraction

Fig. 9. SEM image of turmeric and its solid residues after $\mathrm{USC}_{-} \mathrm{CO}_{2}$, SoxEtOH, and SoxHexane extraction.

\subsection{Characterization of Residue}

The turmeric particle contains cellulose, hemicellulose, lignin, protein, lipid, starch and aromatic substances [27]. After extraction, the physical and chemical component of turmeric might change. Therefore, the properties of residue after extraction will be useful to understand about the effect of ultrasound in $\mathrm{SC}-\mathrm{CO} 2$ extraction. Characterization of residues was determined by using TG and FT-IR. Figure 10 shows the TG curves of turmeric and its residue after $\mathrm{USC}-\mathrm{CO}_{2}, \mathrm{SoxEtOH}$, and SoxHexane extraction. The decomposition of turmeric and its residue were divided into three stages. First stage is ranging from 40 to $120^{\circ} \mathrm{C}$. At this stage, the water and volatile compounds in turmeric were evaporated. The stage II, ranging approximately from 180 to $350{ }^{\circ} \mathrm{C}$, the weight loss was observed due to degradation carbohydrates in lignin, converting into volatile gases such as $\mathrm{CO}, \mathrm{CO}_{2}, \mathrm{CH}_{4}$. The stage $\mathrm{III}$, ranging from 350 to $500{ }^{\circ} \mathrm{C}$, the weight losses also happened because the degradation of volatile compounds derived from lignin (Phenolic, alcohols, aldehyde acid and formation of gaseous products) was removed from sample [28, 29]. Other than that, it also could be seen that the TG curves of solid residue after USC-CO 2 was higher than that of the turmeric and its residue after SoxHexane extraction, but lower than that of the solid residue after SoxEtOH extraction. This can explained that the solid residue after $\mathrm{USC}-\mathrm{CO}_{2}$ had the small amount of cell wall components because some of components was extracted and degraded by ultrasound during USC-CO 2 extraction. Figure 11 illustrates the FT-IR of turmeric and its residue after USC-CO, SoxEtOH and SoxHexane extraction. The list of typical functional group and IR signal with possible compounds was given in work of Kodama et al. 2015 [30]. Based on this figure, it is clearly understand that the peak spectrum in the region $3600-3000 \mathrm{~cm}^{-1}$ represents $\mathrm{O}-\mathrm{H}$ stretching in cellulose was found in all samples. The intensity of these peaks decreased in solid residues after extraction. The prominent band at $2860-2970 \mathrm{~cm}^{-1}$ is attributable to the $\mathrm{C}-\mathrm{H}_{\mathrm{n}}$ stretching was obtained. This suggested that the residue also have aromatic 
structure. The peak at $1625 \mathrm{~cm}^{-1}$ representing $\mathrm{C}=\mathrm{C}$, indicating the benzene stretching ring still found in the solid residue. The peak at region $1601 \mathrm{~cm}^{-1}$ reflecting $\mathrm{C}=\mathrm{C}$ stretching was found in turmeric and its residue after SoxHexane, however it was disappeared in the residue after USC- $\mathrm{CO}_{2}$ and SoxEtOH extraction. This implied that the aromatic skeletal mode was taken away from solid residue after $\mathrm{USC}-\mathrm{CO}_{2}$ and SoxEtOH extraction. The sharp peak in region at 1510-1560 and $1375 \mathrm{~cm}^{-1}$ indicated to $\mathrm{C}=\mathrm{O}$ stretching and $\mathrm{C}-\mathrm{H}$ bending respectively, were found in all solid residue after extraction with low intensity. The peak at 14701430, 1280, $1206 \mathrm{~cm}^{-1}$ are ascribed to $\mathrm{O}-\mathrm{CH}_{3}$, C-O-C stretching, C-O stretching presented in the solid residue after SoxHexane, but disappeared in the solid residues after USC-CO $\mathrm{CO}_{2}$ and SoxEtOH extraction.

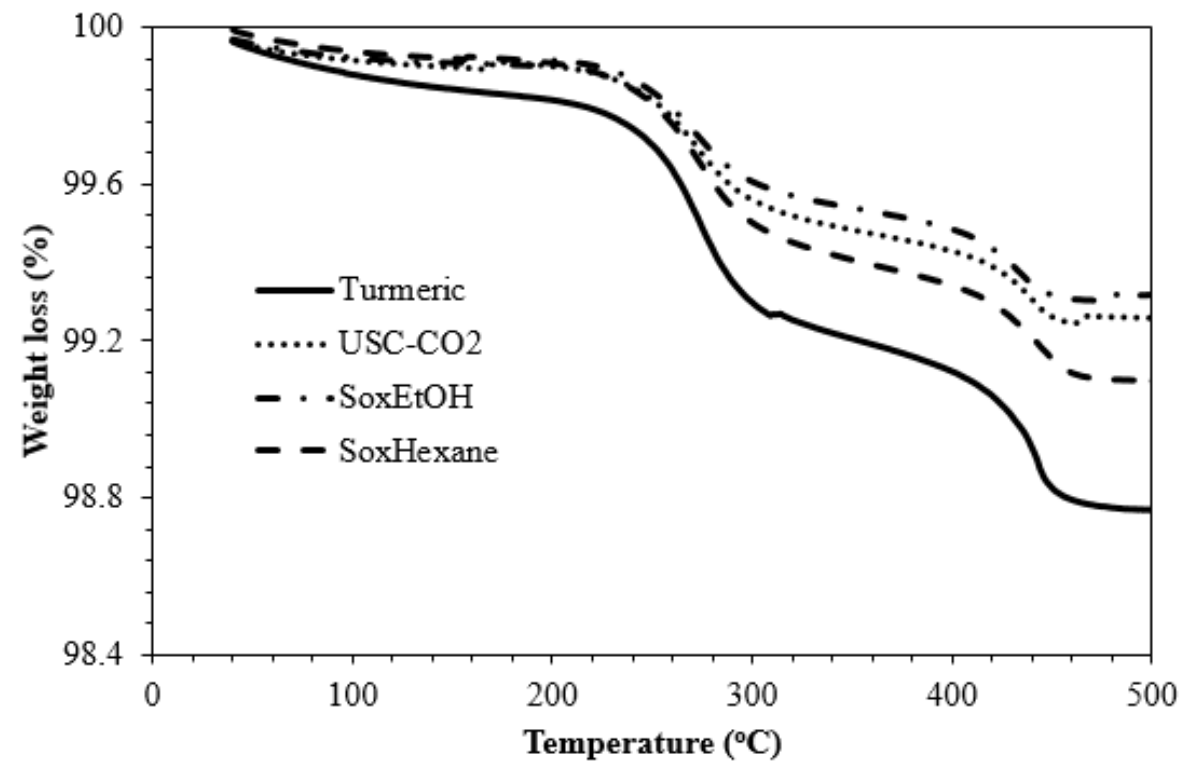

Fig. 10. TG of turmeric and its solid residues after USC-CO, SoxEtOH, and SoxHexane extraction.

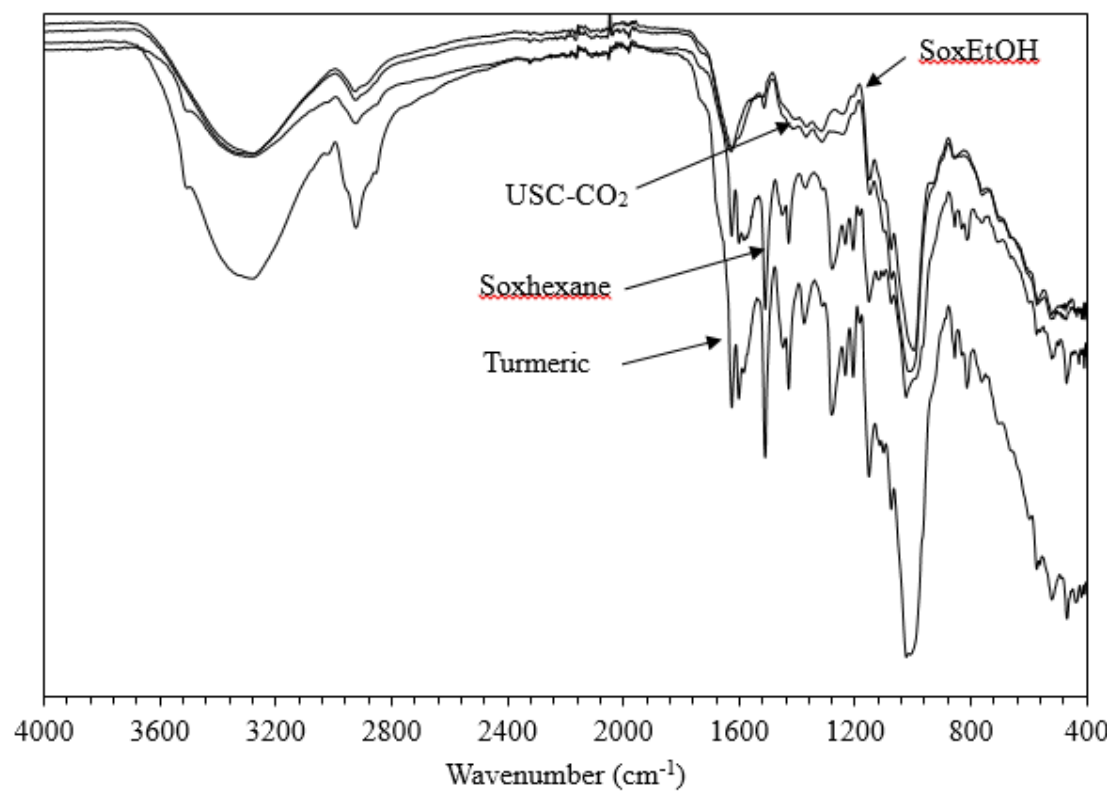

Fig. 11. FT-IR of turmeric and its solid residues after USC-CO $\mathrm{CO}_{2}$, SoxEtOH, and SoxHexane extraction.

The peak at 1152 and $1023 \mathrm{~cm}^{-1}$ are due to $\mathrm{C}-\mathrm{O}-\mathrm{C}$ stretching vibration and $\mathrm{C}-\mathrm{O}$ deformation respectively. The intensity of this peak fell down in all solid residues. The peaks at the region between 700$900 \mathrm{~cm}^{-1}$ indicating to $\mathrm{C}-\mathrm{H}$ was appeared in turmeric and its solid residue after SoxHexane, however it was 
vanished in treated residue with USC- $\mathrm{CO}_{2}$ and SoxEtOH extraction, indicating that the aromatic-hydrogen was removed from material after USC- $\mathrm{CO}_{2}$ and SoxEtOH extraction. Based on current results, it can be concluded that USC- $\mathrm{CO}_{2}$ and SoxEtOH have power to remove more functional group from turmeric compared to SoxHexane extraction. Addition of ultrasound to $\mathrm{SC}-\mathrm{CO}_{2}$ could breakdown cell wall and improved the mass transfer. This could remove some functional groups from cell wall, thus improved the extraction yield.

\section{Conclusions}

USC- $\mathrm{CO}_{2}$ has been used to extract the curcumin from turmeric. The extraction was performed at $40-60{ }^{\circ} \mathrm{C}$, $15-25 \mathrm{MPa}, \mathrm{CO}_{2}$ flow rate of $2-4 \mathrm{~mL} / \mathrm{min}$, cosolvent of $10-20 \%$ and extraction time of $30-120 \mathrm{~min}$. The temperature, pressure and $\mathrm{CO}_{2}$ flow rate and extraction had significant effect on extraction yield and curcumin content while the cosolvent had small effect on extraction yield and curcumin content. The high extraction yield of $7.17 \% \mathrm{w} / \mathrm{w}$ and curcumin of $1.69 \% \mathrm{w} / \mathrm{w}$ as achieved at $50{ }^{\circ} \mathrm{C}, 25 \mathrm{MPa}, \mathrm{CO}_{2}$ flow rate of $3 \mathrm{~mL} / \mathrm{min}$ with $10 \%$ cosolvent, and extraction time of $90 \mathrm{~min}$. Based on results of FT-IR, the intensity of some bands was decreased and some bands were disappeared, indicating that some components in turmeric were removed during USC- $\mathrm{CO}_{2}$ extraction process. Compared to conventional method, USC-CO 2 could provide higher selectivity in extract. Addition of ultrasound in $\mathrm{SC}-\mathrm{CO}_{2}$ extraction process could improve both quality and quantity curcumin in extract from turmeric in a short extraction time.

\section{Acknowledgements}

This research is supported by ASEAN University Network for Southeast Asia Engineering Education Development Network (AUN/SEED-Net) project through the Japan International Cooperation Agency (JICA) and the Precursory Research for Embryonic Science and Technology Program of the Japan Science and Technology Agency (JST).

\section{References}

[1] M. A. Euteripio, C. Cavaliere, A. K. Capriotti, and C. Crescenzi, "Extending the applicability of pressurized hot water extraction to compounds exhibiting limited water solubility by $\mathrm{pH}$ control: curcumin from the turmeric rhizome," Anal Bioanal Chem., vol. 401, no. 9, pp. 2977-2985, Nov. 2011.

[2] R. M. Martrins, S. V. Pereira, S. Siqueira, W. F. salomão, and L. A. P. Freitas, "Curcuminoid content and antioxidant activity in spray dried microparticles containing turmeric extract," Food Res Int., vol. 50, no. 2, pp. 657-663, Mar. 2013.

[3] J. F. Osorio-Tobón, P. I. N. Carvalho, M. A. Rostagno, A. J. Petenate, and M. A. A. M. Meireles, "Extraction of curcuminoids from deflavored turmeric (Curcuma longa L.) using pressurized liquid: Process integration and economic evaluation," J Supercrit Fluids, vol. 95, pp. 167-174, Nov. 2014.

[4] W. M. Giufrida, R. Favareto, V. F. Cabral, M. A. A. Meireles, L. Cardozo-Filho, and M. L. Corazza, "High-pressure vapor-liquid equilibrium data for ternary system $\mathrm{CO}_{2}+$ organic solvent + curcumin," Open Chem Eng J., vol. 4, pp. 3-10, 2010.

[5] M. Xie, D. Fan, Z. Zhao, Z. Li, G. Li, Y. Chen, X. He, A. Chen, J. Li, X. Lin, M. Zhi, Y. Li, and P. Lan, "Nano-curcumin prepared via supercritical: Improve anti-bacterial, anti-oxidant and anti-cancer efficacy," Int J Pharm., vol. 496, no. 2, pp. 732-740, Dec. 2015.

[6] M. V. Kiamahalleh, G. Najafpour-Darzi, M. Rahimnejah, A. A. Moghadamnia, and M. V. Kiamahalleh, "High performance curcumin subcritical water extraction form turmeric (Curcuma longa L.)," J Chromatogr B., vol. 1022, pp. 191-198, Jun. 2016.

[7] F. Chemat and M. K. Khan, "Application of ultrasound in food technology: Processing, preservation and extraction," Ultrason Sonochem., vol. 18, no. 4, pp. 813-835, Jul. 2011.

[8] J. Azmir, I. S. M. Zaidul, M. M. Rahman, K. M. Sharif, A. Mohamed, F. Sahena, M. H. A. Jahurul, K. Ghafoor, N. A. N. Norulaini, and A. K. M. Omar, "Techniques for extraction of bioactive compounds from plant material: A review," J Food Eng., vol. 117, no. 4, pp. 426-436, Aug. 2013.

[9] B. Gopalan, M. Goto, A. Kodama, and T. Hirose, "Supercritical carbon dioxide extraction of Turmeric (Curcuma longa)," J. Agric. Food Chem., vol. 48, no. 6, pp. 2189-2192, Jun. 2000. 
[10] J. L. P. Reátegui, A. P. D. F. Machado, G. F. Barbero, C. A Rezende, and J. martínez, "Extraction of antioxidant compounds from blackberry (Rubus sp.) bagasse using supercritical $\mathrm{CO}_{2}$ assisted by ultrasound," J Supercrit. Fluids, vol. 94, pp. 223-233, Oct. 2014.

[11] P. Santos, A. C. Aguiar, G. F. Barbero, C. A. Rezende, and J. Martínez, "Supercritical carbon dioxide extraction of capsaicinoids from malagueta paper (Capsicum frutescens L.) assisted by ultrasound," Ultrason Sonochem., vol. 22, pp.78-88, Jan. 2015.

[12] A. Hu, S. Zhao, H. Liang, T. Qiu, and G. Chen, "Ultrasound assisted supercritical fluid extraction and coixenolide from adlay seed," Ultrason Sonochem., vol. 14, no. 2, pp. 219-224, Feb. 2007.

[13] Y. Yang, M. Wei, S. Hong, T. Huang, and S. Lee, "Development/optimization of a green procedure with ultrasound-assisted improved supercritical carbon dioxide to produce extracts enriched in oleanolic acid and ursolic acid from Scutellaria barbata D. Don," Ind Crops Prod., vol. 49, pp. 542-553, Aug. 2013.

[14] C. D. Porto, A. Natolino, and D. Decorti, "The combined extraction of polyphenols from grape marc: Ultrasound assisted extraction followed by supercritical $\mathrm{CO}_{2}$ extraction of ultrasound-raffinate," Food Sci Technol., vol. 61, no. 1, pp. 98-104, Apr. 2015.

[15] P. dos Santos, A. C. de Aguiar, J. Viganó, J.S. Boeing, J. V. Visentainer, and J. Martínez, "Supercritical $\mathrm{CO}_{2}$ extraction of cumbaru oil (Dipteryx alata Vogel) assisted by ultrasound: Global yield, kinetics and fatty acid composition," J Supercrit. Fluids, vol. 107, pp. 75-83, Jan. 2016.

[16] M. Wei, J. Xiao, and Y. Yang, "Extraction of $\alpha$-humulene-riched oil form clove using ultrasoundassisted supercritical carbon dioxide extraction and studies of its fictitious solubility," Food Chem., vol. 210, pp. 172-181, Nov. 2016.

[17] Y. Yang and M. Wei, "A combined procedure of ultrasound-assisted and supercritical carbon dioxide for extraction and quantitation oleanolic and ursolic acids from Hedyotis corymbosa". Ind Crops Prod., vol. 79, pp. 7-17, Jan. 2016.

[18] H. Kawamura, K. Mishima, T. Sharmin, S. Ito, R. Kawakami, T. Kato, M. Misumi, T. Suetsugu, H. Orii, H. Kawano, K. Irie, K. Sano, K. Mishima, T. Harada, S. Mustofa, F. Hasanah, Y. D. I. Siregar, H. Zahroh, L. S. E. Putri, and A. Salim, "Ultrasonically enhance extraction of luteolin and apigenin from the leaves of Perilla frutescens (L.) Britt. Using carbon dioxide and ethanol," Ultrason Sonochem., vol. 29, pp. 19-26, Mar. 2016.

[19] M. Goto, H. Kanda, Wahyudiono, and S. Machmudah, "Extraction of carotenoids and lipids from algae by supercritical carbon dioxide and subcritical dimethyl ether," J Supercrit. Fluids, vol. 96, pp. 245-251, Jan. 2015.

[20] K. Chhouk, A. T. Quitain, P. D. Gaspillo, J. B. Maridable, M. Sasaki, Y. Shimoyama, and M. Goto, "Supercritical carbon dioxide-mediated hydrothermal extraction of bioactive compounds from Garcinia Mangostana pericarp," J Supercrit. Fluids, vol. 110, pp. 167-175, Apr. 2016.

[21] S. Balachandran, E. Kentish, R. Mawson, and M. Ashokkumar, "Ultrasonic enhancement of the supercritical fluid extraction from ginger," Ultrason Sonochem., vol. 13, no. 6, pp. 471-479, Sep. 2006.

[22] Y. Tao, Q. Zhang, and D. Sun, "Ultrasound-assisted extraction of phenolics from wine lees: Modeling, optimization and stability of extracts during storage," Ultrason Sonochem., vol. 21, no. 2, pp. 706-715, Mar. 2014.

[23] M. E. M. Braga and M. A. A. Meireles, "Accelerated solvent extraction and fractioned extraction to obtain the Curcuma longa volatile oil and oleoresin," J Food Proc Eng., vol. 30, no. 4, pp. 501-521, Aug. 2007.

[24] H. Kazazi, K. Rezaei, S.J. Ghotb-Sharif, and Z. Emam-Djomeh, "Supercritical fluid extraction of flavors and fragrances from Hyssopus officinalis L. cultivated in Iran," Food Chem., vol. 105, no. 2, pp. 805-811, Dec. 2007.

[25] J. Ji, X. Lu, M. Cai, and Z. Xu, "Improvement of leaching process of Geniposide with ultrasound," Ultrason Sonochem., vol. 13, no. 5, pp. 455-462, Jul. 2006.

[26] M. Vinatoru, "An overview of the ultrasonically assisted extraction of bioactive principles from herbs," Ultrason Sonochem., vol. 8, no. 3, pp. 303-313, Jul. 2001.

[27] B. C. Maniglia, J. R. Domingos, R. L. Poula, and D. R. Tapia-Blácido, "Development of bioactive edible film from turmeric dye solvent extraction residue," LWT-Food Sci Technol., vol. 56, no. 2, pp. 269-277, May 2014. 
[28] A. Tejado, C. Peña, J. Labidi, J. M. Echeverria, and I. Mondragon, "Physico-chemical characterization of lignons from different sources for use in phenol-formaldehyde resin synthesis," Bioresour Technol., vol. 98, no. 8, pp. 1655-1663, May 2007.

[29] D. Watkins, M. Muruddin, M. Hosur, A. Tcherbi-Narteh, and S. Jeelani, "Extraction and characterization of lignin from different biomass," J Mater Res Technol., vol. 4, no. 1, pp. 26-32, Mar. 2015.

[30] S. Kodama, T. Shoda, S. Machmudah, Wahyudiono, H. Kanda, and M. Goto. "Enhancing pressurized water extraction of $\beta$-glucan from barley grain by adding $\mathrm{CO}_{2}$ under hydrothermal conditions," Chem Eng Process Process Intensif., vol. 97, pp. 45-54, Nov. 2015. 